HAIBO WANG, Ph.D. ${ }^{1}$

E-mail: sdlgwanghaibo@sohu.com

HAIQING SI, Ph.D. ${ }^{1}$

(Corresponding author)

E-mail: sihaiqing@126.com

YAO LI, Ph.D. ${ }^{1}$

E-mail: liyao33355555@163.com

TING PAN, Ph.D. ${ }^{1}$

E-mail: panting3721@163.com

YITONG ZONG ${ }^{1}$

E-mail: yitongzyt@163.com

NAIQI JIANG ${ }^{1}$

E-mail: woshitiancai0816@163.com

${ }^{1}$ School of Civil Aviation and Flight

Nanjing University of Aeronautics and Astronautics

Nanjing 211106, China
Human - Transport Interaction

Preliminary Communication

Submitted: 22 Apr. 2019

Accepted: 3 Oct. 2019

\title{
ANALYSIS OF DYNAMIC CHARACTERISTICS OF PILOTS UNDER DIFFERENT INTENTIONS IN COMPLEX FLIGHT ENVIRONMENT
}

\begin{abstract}
Intention is the main embodiment of human cerebral conscious activities, which has an important influence on guiding the realization of human behaviour. It is a vital prerequisite for analysing the dynamic characteristics of pilots with different intentions. Considering the intention law of the generation, transfer and reduction, this paper analyses dynamic characteristics of pilots with different intentions, starting from the factors of effect on the intention. Taking airfield traffic pattern as an example for simulating flight experiments, the pilot's multi-source dynamic data of human - aircraft - environment system under different intentions and their psycho-physiological-physical characteristics were recorded. Based on Matlab, one-way analysis of variance was used to extract variables with significant changes, and the variables under different intentions were compared and analysed. The results show that the conventional pilots are more conducive to control the aircraft to keep a stable flight attitude. This study is of great significance for perfecting the warning system of flight safety and improving the pilot's micro-behaviour assessment system.
\end{abstract}

\section{KEY WORDS}

flight safety; pilot's intention; dynamic characteristics; one-way analysis of variance;

\section{INTRODUCTION}

As air-transport industry has been developing vigorously, the number of flights has gradually increased. Although the accident rate of air-transport has declined annually, air-transport accidents still exist. Previous air-transport accident investigations showed that more than $70 \%$ of accidents were caused by human factors, among which more than $35 \%$ resulted from pilots' mistakes [1-4]. Therefore, it is significant to control the pilot's microscopic behaviour for flight safety. Micro-behaviour is mainly an individual characteristic of the pilot. The pilots' intentions determine their behaviour at the next moment. In order to identify the pilots' intentions, perfect the early-warning system of flight safety, and establish the pilot's micro-behaviour assessment system, it is essential to acquire the physiological, psychological, and physical characteristics accurately.

The domestic and foreign scholars have done many studies on microscopic features of the pilots including physiological, psychological and physical characteristics. Based on the data of the heart rate, galvanic skin reflex, blink frequency, and brain wave during the pilots' flights, Glenn [5] used a multi-dimensional psychological-physiological analysis method to study the mental workload of pilots under the complex flight missions. From the view of the pilots establishing reasonable situational awareness when facing loss of control-in-flight (LOC-I), the powerful Upset Prevention and Recovery Training (UPRT) model proposed by Schlimm [6] enables pilots to sense in advance and make correct decisions in the face of threats. The EMG 
(Electromyography) of the pilots during the flight simulation, the flight training of the pilots in special environment (e.g. take-off and landing of seaborne carrier aircraft) was evaluated by Zhang et al. [7]. The results indicate that effective training reduces the muscle fatigue of pilots and thus contributes to the success of the mission. For the purpose of identifying the pilots' differences between dynamic and static modes, Jia et al. [8], employed diffusion mapping and kernel fuzzy C-means (KFCM) methods and processed the data collected under manual handling of aircraft approach missions. The analysis of the mutual correlation of the pilot's heart rate, respiration, pupil diameter, facial thermal imaging and mental workload have been done by Marinescu et al. [9]. The result is theoretically important to design, operation of the aircraft cockpit and the reduction of pilot's cognitive load in the future. Olivari et al. [10] adopted the regular recursive least squares method to identify the time-varying response of the pilot's visual and force feedback during the compensatory tracking task. It shows that this method can be used to estimate the response of time-varying pilots in the real human loop experiment. The hybrid multiagent strategy discovery algorithm (HMASDA) is used by Tavcar et al. [11] to study how the pilots handle different scenarios. In this study, the cognitive process and behaviour of pilots in different conflict scenarios can be obtained by the simulation system. According to the typical correlation analysis method, Jaquess et al. [12] analysed the pilot's heart rate, EEG (electroencephalograph) and other characteristics, which show that the pilot's attention reserve decreased with the increase of task demand and cognitive load. Lampton et al. [13] explored the issue of spatial orientation obstacles in pilots during the go-around. They obtained the physiological indicators, such as the heart rate of the pilot through the NASA-certified D-class Boeing 747 simulator, and studied the spatial orientation and situational awareness of the subjects. In order to address the safety issues in flight, the eye movements of the pilots in unexpected flight conditions in the glass cockpit were studied by Russi-Vigoya et al. [14], which would provide a theoretical basis for determining the visual characteristics of pilots under the adverse conditions.

Previous research analysed the individual microscopic characteristics from a relatively macroscopic and static point of view, such as the pilot's prospective memory, attention, manual mode, and driving fatigue. To a certain extent, they promoted the development of pilot's micro-behaviour. However, they had not studied the relationship of the pilot's internal mechanism changes and external behaviour in depth. The relationship between the pilot's internal mechanism changes and external behaviour have not been studied thoroughly, such as the change of the dynamic characteristics of pilots in the human - aircraft - environment complex system (the human - aircraft - environment system mainly consists of two parts: objective factors and subjective factors). The dynamic characteristics of pilots include physiological, psychological, and physical features. Therefore, this paper introduces the concept of flight intentions, and defines the acceleration, deceleration, maintaining speed, climb, descent, maintaining altitude, turning left, turning right and maintaining course in three dimensions. Besides, the dynamic characteristics of pilots under different intentions are analysed in a complex flight environment. Taking the airfield traffic pattern as an example, the non-invasive natural driving experiment (real aircraft experiment and simulation experiment) is conducted from the pilot's performance. The pilot's multi-source microscopic dynamic characteristics data are collected, and the psychological and physiological characteristics are gathered statistically. One-way analysis of variance (one-way ANOVA) is applied to extract pilot's different variables and compare the characteristics of each movement with different intentions on Matlab. It provides a basis for further study of intentions and micro-behaviour assessment of pilots and the active safety warning of flight.

\section{METHOD}

\subsection{Factors analysis affecting pilot's intention}

With the development of advanced flight deck technologies, pilots have been gradually released from heavy flight control. Nevertheless, with the integration of information, pilots still act as the core of aircraft control and bear the burden of heavy acquisition and processing of information. The process of generation, transfer, and reduction of pilot's intentions in flight is complex. The intention is the result of the pilot's perception, judgement and decision-making on the external information (environment, aircraft, etc.). The intention is ultimately 
transformed into pilot's behaviour, and the pilot achieves control of the aircraft [15], as shown in Figure 1 .

The generation, transfer and reduction of intention are affected by objective factors, including flight environment, aircraft condition, crew, ATC, etc. The human - aircraft - environment system as described in Figure 1, from the pilot's perspective, the aircraft and the environment are objective factors. The aircraft is mainly the state of speed, altitude and heading during the aircraft operation. The environmental factors include the time-varying flight environment and human - aircraft interaction interface. The time-varying flight environment includes macro-information such as the aircraft cockpit environment (e.g. cockpit noise, temperature, humidity, vibration, etc.) and the external cockpit environment (e.g. weather, wind, runway conditions, air traffic flow, etc.). The information of human - aircraft interaction includes micro-information of interactions between pilots and cockpit hardware, software, and crew.

The physiological, psychological, and physical characteristics of the pilot are subjective factors that are affected by these objective factors. These intrinsic physiological-psychological changes and external physical behaviours are all connected by intention. The intention can transform the intrinsic changes of pilots into external behaviours. For example, the pilot's consciousness of turning left or right had been produced before the rudder is manipulated.

In addition to the objective factors that are obtained from the perception, the physiological and psychological characteristics of pilots are also important factors affecting the pilot's intention. The healthy status, personality, and circadian rhythm of pilots are different, and there are differences in the cognitive ability of the external environment and the changes in the inner sentiment. In the same environment, the pilot will also have different intentions.

\subsection{Pilot's intention}

The intention is the brain comprehensive reaction of the pilot's physiological, psychological, and physical characteristics under objective flight conditions. The intention is the internal dynamics that promotes the pilot's behaviour, and decides about the pilot's choice and direction of the surrounding environment.

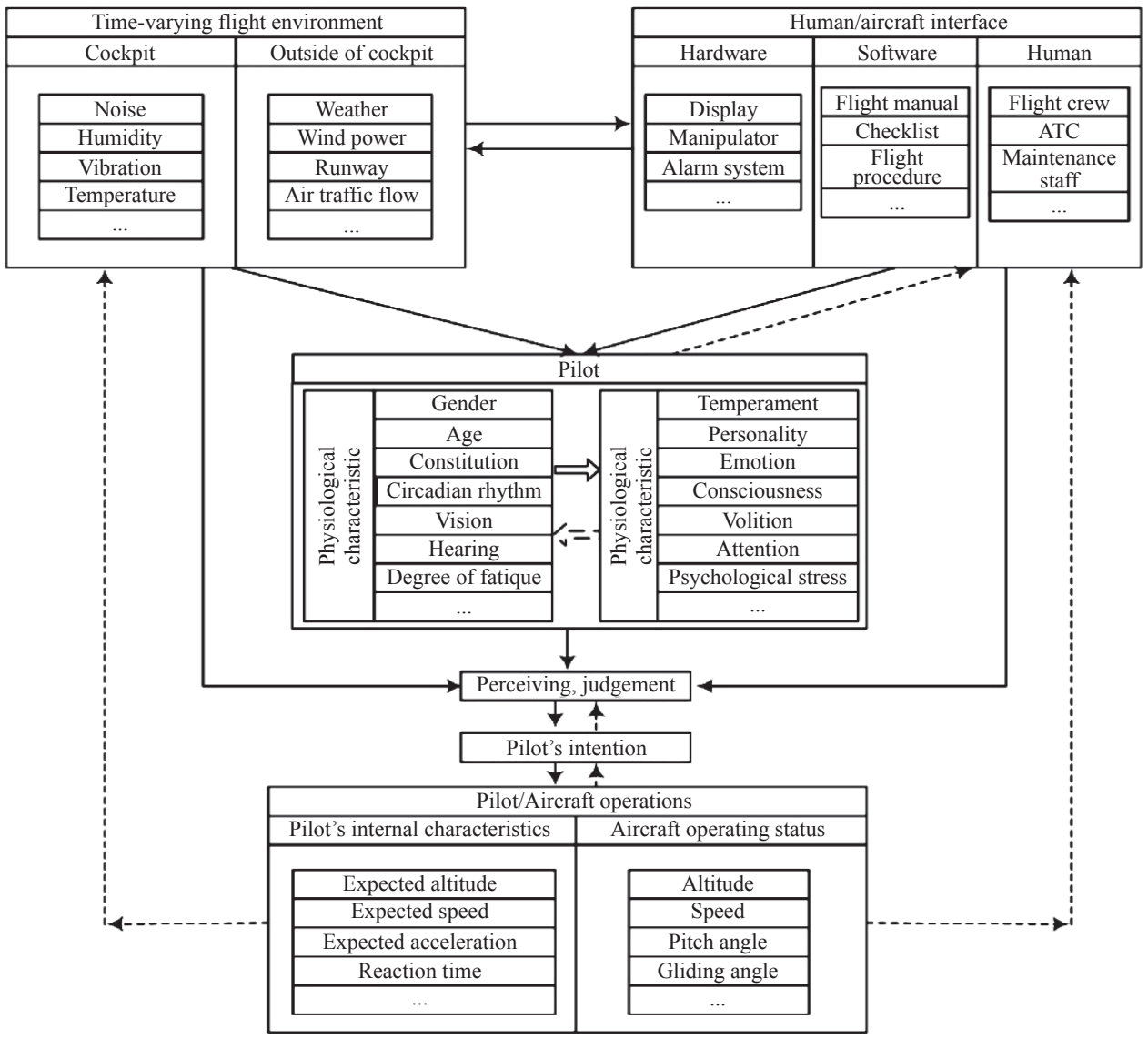

Figure 1-Conversion diagram of pilot's intention 
The intention can be regarded as an advance planning of the next manipulative behaviour and a kind of decision on the current information acquired. The pilot's decision combines the subjective wishes, flight experience, regulations and the operating habits. Its purpose is to guide the execution of the pilot's subsequent manipulations. In general, the pilot's intention is to comply with flight regulations as far as possible and to ensure smooth and safe operation of the aircraft. Due to the significant differences of the pilots in the physiological, psychological, and physical aspects, different pilots would not have the same intentions under various flight environments and uniform flight regulations. The pilot's intentions are simply defined as speed intention $\left(I_{1}\right)$, lateral intention $\left(I_{2}\right)$, and vertical intention $\left(I_{3}\right)$ in this paper, which constitute the three-dimensional pilot's intention sets $\Gamma=\left(I_{1}, I_{2}, I_{3}\right)$ in this paper. Each set of consecutive intentions is divided into three mutually exclusive discrete domains. They are listed in Table 1.

\subsection{Experimental design}

The sample size of the experiment was 75 male flying cadets who had obtained a Private Personal Pilot License, Commercial Pilot License and Instrument Rating License. Their age ranged from 25 to 30 and the mean value is 27 . They had $250-300$ hours of flight experience.

The dynamic acquisition system for comprehensive information (including PsyLAB Human Sensor, Polar Watch, etc.), the high-simulation flight aircraft (consisting mainly of 12 high-fidelity Cessna 172 flight simulators) and Cessna 172 aircraft were utilized to collect the data in the experiment, as shown in Figures 2, $3 a$ and $3 b$.

Table 1 -Pilot's intention set

\begin{tabular}{||c|c|c||}
\hline Speed intention $\left(I_{1}\right)$ & Lateral intention $\left(I_{2}\right)$ & Vertical intention $\left(I_{3}\right)$ \\
\hline \hline Accelerate intention $\left(I_{11}\right)$ & Turn left intention $\left(I_{21}\right)$ & Climb intention $\left(I_{31}\right)$ \\
\hline Decelerate intention $\left(I_{12}\right)$ & Turn right intention $\left(I_{22}\right)$ & Descend intention $\left(I_{32}\right)$ \\
\hline Constant speed intention $\left(I_{13}\right)$ & Constant heading intention $\left(I_{23}\right)$ & Constant altitude intention $\left(I_{33}\right)$ \\
\hline
\end{tabular}

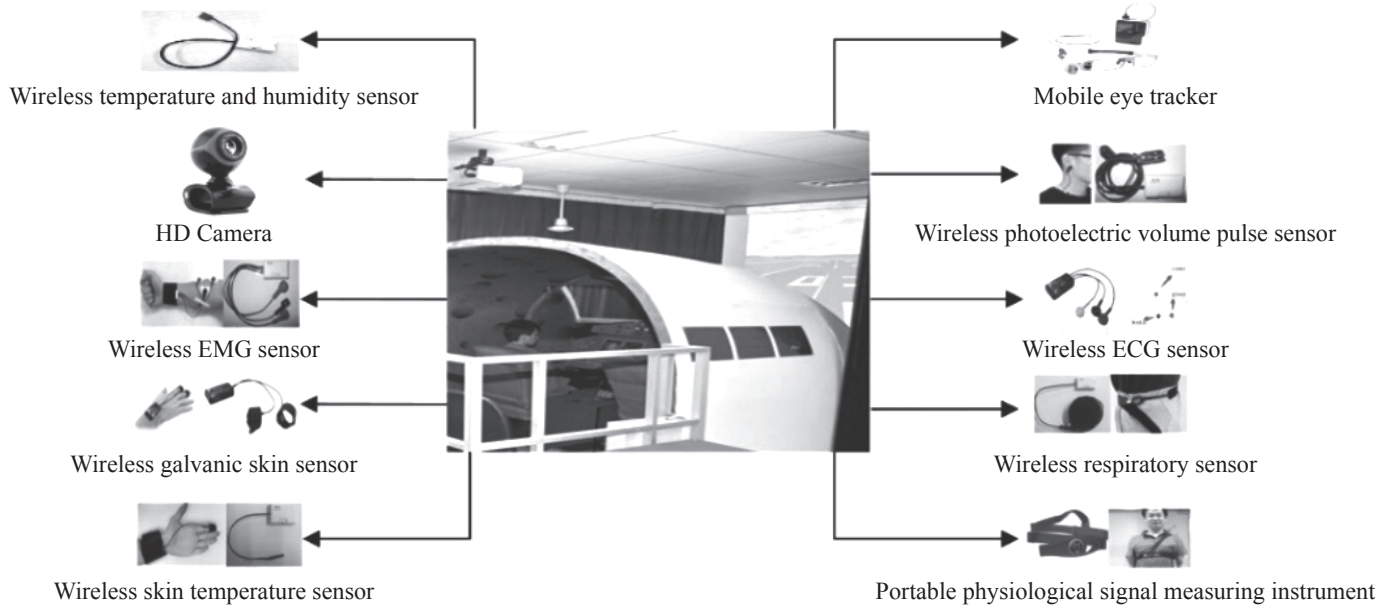

Figure 2-Dynamic acquisition system for comprehensive information

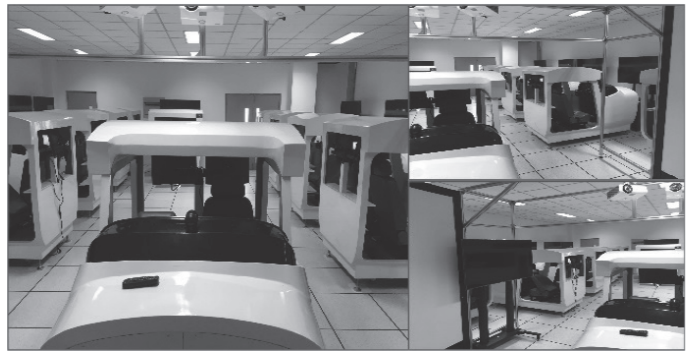

a) Cessna 172 flight simulator

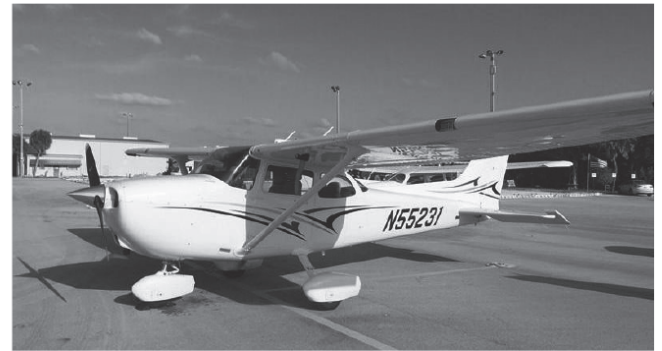

b) Cessna 172 aircraft

Figure 3 - Experimental platform 
The experiment was carried out at a good airport, regarding weather, visibility, etc. An airport was selected as an experiment site for the airfield traffic pattern. Google Maps software and Explorer V900 portable GPS software were utilized to analyse the flight trajectory data, as depicted in Figure 4. According to the real aircraft flight, a high-simulation flight platform was adopted to build a virtual environment (as indicated in Figure 5).

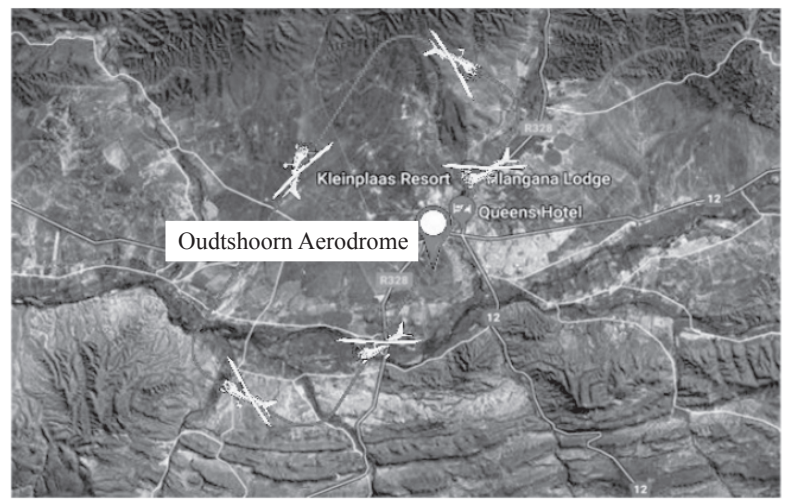

Figure 4-Diagram of real airfield traffic pattern

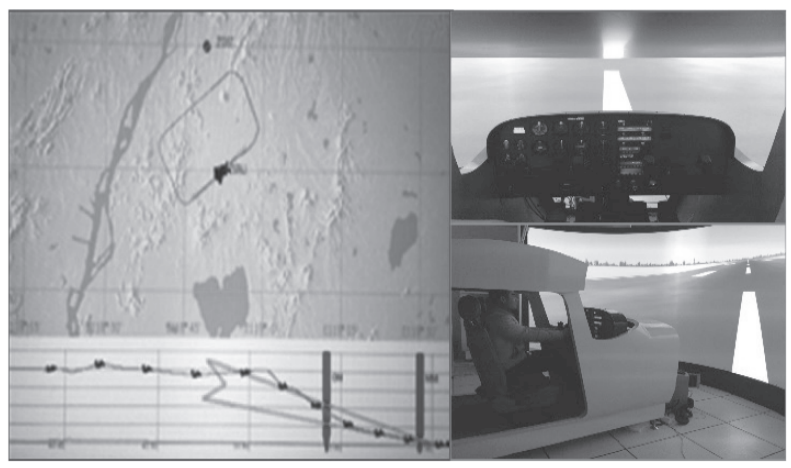

Figure 5-Diagram of simulation

\section{Pilot's psychological-physiological test}

The inherent and intrinsic psychological-physiological characteristics of pilots are the main factor which affects the pilot's intentions. The pilot's manipulative behaviour will also be affected by these characteristics ultimately. The pilot's psychological and physiological test experimental steps are as follows:

1) The basic information of the subjects was obtained through questionnaires, including name, gender, age, flight hours, type of pilot's psychological characteristics, etc. (pilot's psychological questionnaire is shown in Table 2). This study was approved by the local institutional review board, and a written informed consent was obtained from all the participants.
2) Using the dynamic acquisition system for comprehensive information to obtain the pilot's operational response time and speed estimation ability is the focus of this physiological indicator test [16] (the specific test method is described in Table 3). Each pilot was tested in ten groups, and each group was tested fifteen times. The average time was taken as the pilot's response time. The speed estimation capability was measured five times per person and the average was taken as the estimated time.

\section{Real aircraft and simulation flight experiment}

The data obtained from the simulation experiment are closer to the pilot's natural driving. The experimental organization of real aircraft is rather difficult and the cycle is long, so it is difficult to obtain large amounts of data. The real aircraft data of Cessna 172 are mainly obtained from flight video and the instructor's feedback. The simulation flight experiment can easily acquire a lot of flight data. Therefore, the experimental platform of simulation flight is applied to simulate the airfield traffic pattern and construct a virtual route. The simulation flight experiment is carried out, and the experimental data can be supplemented. The specific process of the experiment is described in Figure 6.

In order to ensure smooth progress of the experiment, the experimental equipment is installed, connected, and debugged. The pilots underwent a flight training before the experiment in accordance with the matters needing attention.

The pilot's intention is a process of generation $\rightarrow$ transfer $\rightarrow$ reduction in the human brain. For example, the pilots completed the airfield traffic pattern according to the flight procedure given in Figure 7, with their intentions constantly changing.

The pilot's intention in controlling the flight of the aircraft has a process of reduction. When a pilot completes the crosswind leg and turns to the downwind leg at a certain speed, altitude, heading, etc., it also means one intention is reduced with the beginning of another intention, as shown in Figure 7. At the end of the flight, the speed, altitude, and heading of the aircraft during the experiment are collected.

The effectiveness of the pilot's intention is determined by the changes of the pilot's intention and the statistical analysis of the pilot's behaviour at different stages, where, after the flight, the former is obtained by a video playback and the instructor's 
Wang H, Si H, Li Y, Pan T, Zong Y, Jiang N. Analysis of Dynamic Characteristics of Pilots Under Different Intentions...

\section{Table 2 -Pilot's psychological questionnaire}

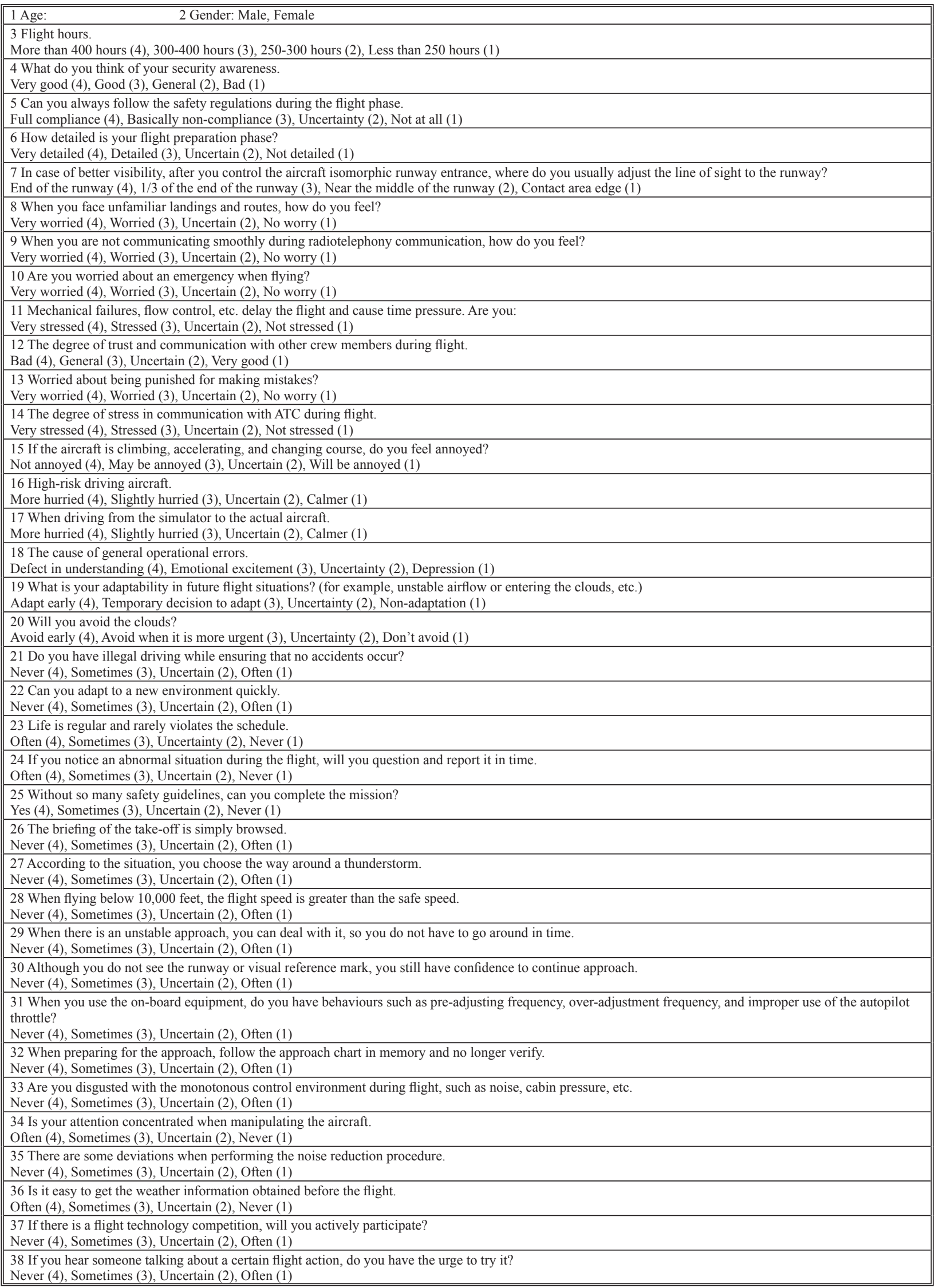

Note: The number in parentheses is the score of the corresponding option. Scores from questions 3 to 38 are introduced next. Radical pilots scored 36 to 69, steady cyclists scored 70 to 101, and Conservative cyclists scored 102 to 144. 
Wang H, Si H, Li Y, Pan T, Zong Y, Jiang N. Analysis of Dynamic Characteristics of Pilots Under Different Intentions...

Table 3 - Test method for partial physiological indicators

\begin{tabular}{||c|l||}
\hline \multicolumn{1}{|c|}{ Indicators } & \multicolumn{1}{c|}{ Test method } \\
\hline \hline Operational response time & $\begin{array}{l}\text { Pilots were measured using a comprehensive response test instrument. Subjects pressed their } \\
\text { right index finger onto the instrument "Home Position" button. After they press the home position } \\
\text { button, there will be six light spots arranged in a semicircle on the screen. The subjects found out } \\
\text { which light was on. They will use the right index finger to press the corresponding 1-6 number } \\
\text { keys on the keyboard, then return to the home position button and hold. }\end{array}$ \\
\hline Speed estimation ability & $\begin{array}{l}\text { Pilots were measured using a DXC-6 multiple psychometric instrument. The screen presents a } \\
\text { light spot that moves from left to right and changes in speed. There is a vertical line in the centre } \\
\text { and right side of the screen. The spot disappears when it moves to the centre vertical line. The } \\
\text { participants were asked to estimate the time at which the spot reached the vertical line on the } \\
\text { right. They press the confirm button at the moment they think the spot touches the vertical line on } \\
\text { the right. }\end{array}$ \\
\hline
\end{tabular}

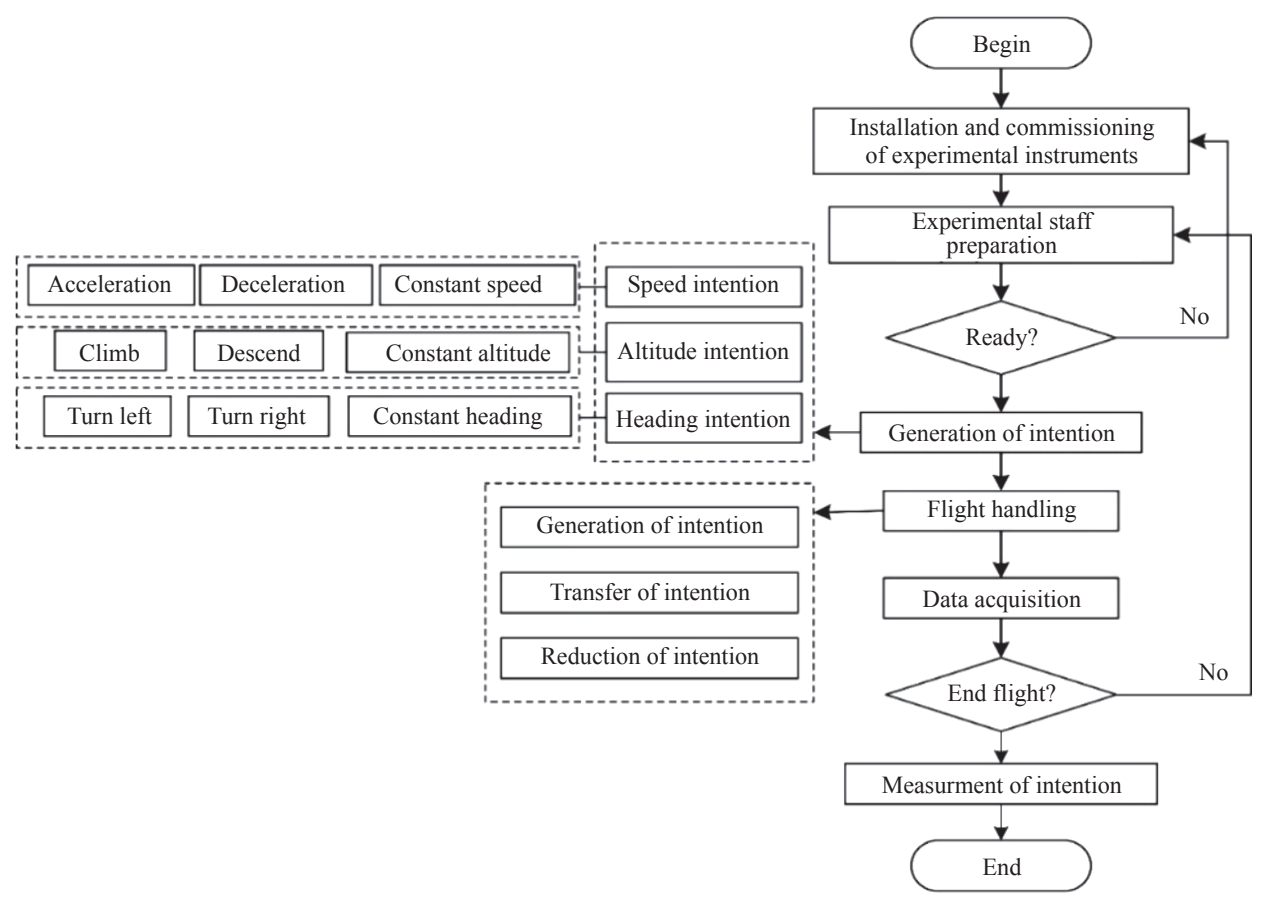

Figure 6- Flow diagram of the flight experiment

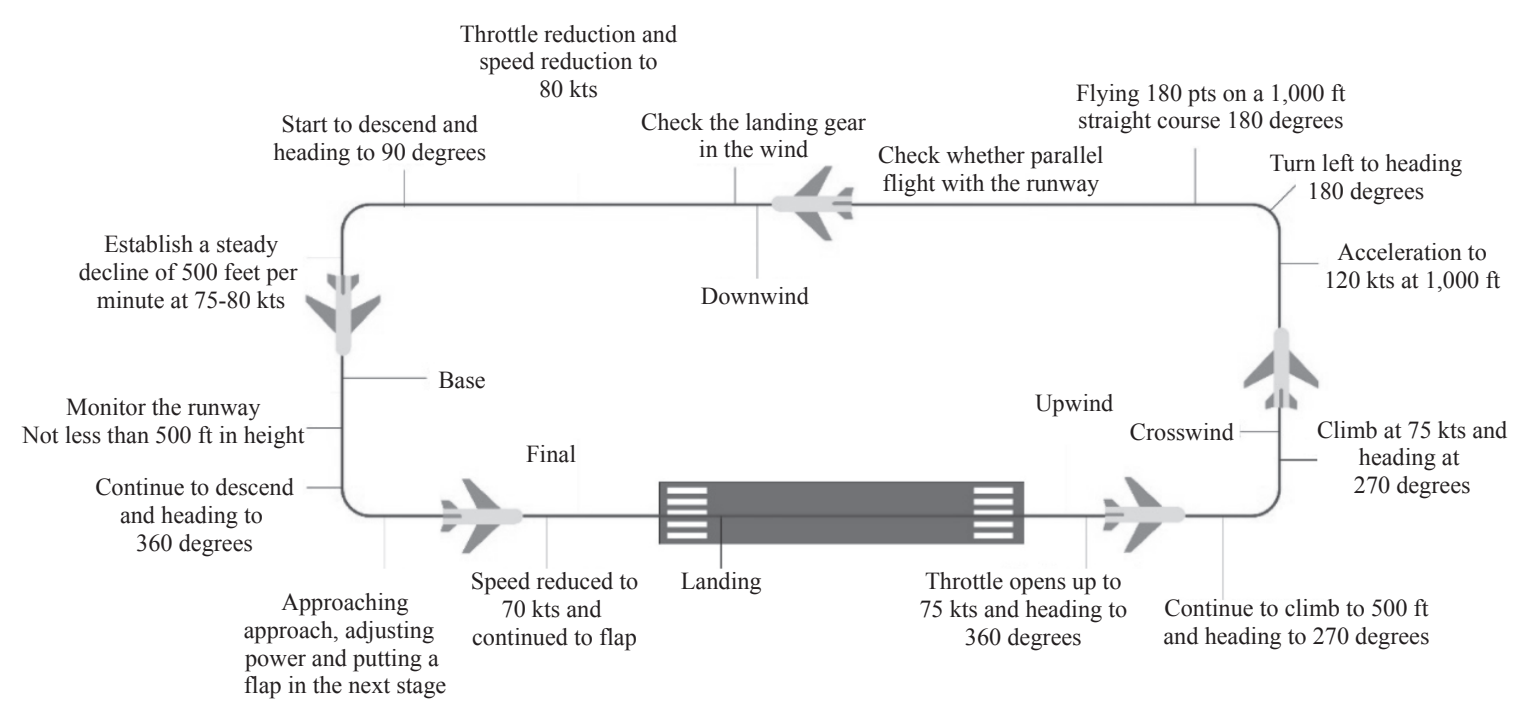

Figure 7 - Cessna 172 flight diagram of the airfield traffic pattern 
Wang H, Si H, Li Y, Pan T, Zong Y, Jiang N. Analysis of Dynamic Characteristics of Pilots Under Different Intentions...

feedback. The latter is derived by combining the pilot's physiological data with the aircraft operational attitude data.

From take-off to the final leg in each airfield traffic pattern, the speed, altitude and heading intention of the pilots change. For example, when moving from the crosswind leg to the downwind leg, the rudder, elevator, throttle, etc. will be adjusted in the light of the flight manual and related regulations. Thereby, the intention of constant speed, constant altitude and constant heading are reduced, and the intention of acceleration, climbing and turning left are further generated. Two sets of experimental data were collected for each intention, and 1,350 sets of experimental data were obtained.

\section{Data processing}

Factors such as the representativeness, reliability and statistical analysis requirements of the test data are taken into account. The original data are processed in turn to exclude 235 samples involving incomplete, unstable, and abnormal data. The remaining 1,115 samples are the final samples determined by the statistical analysis. In order to facilitate subsequent data analysis, some variables are processed to better reflect the characteristics of the pilot's movement without losing data information. The processed variables and symbols can be found in Table 4. Due to space limitations, some experimental data are listed in Table 5.

Table 4 - Variables and symbols in the experiment

\begin{tabular}{|l|c||}
\hline \multicolumn{1}{|c|}{ Variable } & Symbol \\
\hline \hline Gender & $x_{1}$ \\
\hline Age & $x_{2}$ \\
\hline Flight hours & $x_{3}$ \\
\hline Psychological characteristics type & $x_{4}$ \\
\hline Operational reaction time [s] & $x 5$ \\
\hline Speed estimation time [s] & $x_{6}$ \\
\hline Rudder pedal strength [N] & $x_{7}$ \\
\hline Steering column strength [N] & $x_{8}$ \\
\hline Climbing rate [km/s] & $x_{9}$ \\
\hline Accelerating frequency [times/min] & $x_{10}$ \\
\hline Pitch angle [deg] & $x_{11}$ \\
\hline Roll angle [deg] & $x_{12}$ \\
\hline Turn rate [deg/s] & $x_{13}$ \\
\hline Throttle percentage [deg] & $x_{14}$ \\
\hline Vertical speed change frequency [times/min] & $x_{15}$ \\
\hline Horizontal speed change frequency [times/min] & $x_{16}$ \\
\hline
\end{tabular}

Table 5 - Some experimental data

\begin{tabular}{|c|c|c|c|c|c|c|c|c|c|c|}
\hline \multirow{3}{*}{$\begin{array}{c}\text { No. } 1 \\
\text { Intention }\end{array}$} & \multicolumn{2}{|c|}{$x_{1}$} & \multicolumn{2}{|c|}{$x_{2}$} & \multicolumn{2}{|c|}{$x_{3}$} & \multicolumn{2}{|c|}{$x_{4}$} & $x_{5}$ & $x_{6}$ \\
\hline & \multicolumn{2}{|c|}{ Male } & \multicolumn{2}{|c|}{25} & \multicolumn{2}{|c|}{4.6} & \multicolumn{2}{|c|}{ Aggressive type } & 0.46 & 1.0 \\
\hline & $x_{7}$ & $x_{8}$ & $x_{9}$ & $x_{10}$ & $x_{11}$ & $x_{12}$ & $x_{13}$ & $x_{14}$ & $x_{15}$ & $x_{16}$ \\
\hline Acceleration & 36.5 & 21 & 1.50 & 5.4 & 10.7 & 1.2 & 128.3 & 37.8 & "5.29 & 6.22 \\
\hline Deceleration & 36 & 21.5 & 1.65 & 6.7 & 9.2 & 1.1 & 118.9 & 36.5 & 5.20 & 6.19 \\
\hline Constant speed & 36.2 & 22 & 1.46 & 4.3 & 10.8 & 2.1 & 120.5 & 38 & 4.22 & 6.25 \\
\hline Climb & 37 & 22.2 & 1.70 & 8.4 & 20 & 2 & 113.4 & 36.9 & 5.19 & 7.26 \\
\hline Descend & 37.5 & 22 & 1.68 & 8.2 & 15 & 1.5 & 122.5 & 35.7 & 5.25 & 6.17 \\
\hline Constant altitude & 36.6 & 21 & 1.75 & 3.4 & 4 & 1.4 & 110.7 & 37 & 4.18 & 6.25 \\
\hline Turn left & 38 & 21.4 & 1.70 & 6.3 & 6.5 & 2.3 & 125.6 & 35.8 & 3.22 & 7.20 \\
\hline Turn right & 38.5 & 22 & 1.75 & 6.5 & 5.5 & 2.5 & 110.3 & 36 & 4.19 & 7.16 \\
\hline Constant heading & 37.7 & 22.6 & 1.60 & 7.2 & 6 & 1.2 & 123.4 & 36.6 & 5.21 & 7.20 \\
\hline \multirow{2}{*}{ No. 2} & \multicolumn{2}{|c|}{$x_{1}$} & \multicolumn{2}{|c|}{$x_{2}$} & \multicolumn{2}{|c|}{$x_{3}$} & \multicolumn{2}{|c|}{$x_{4}$} & $x_{5}$ & $x_{6}$ \\
\hline & \multicolumn{2}{|c|}{ Male } & \multicolumn{2}{|c|}{29} & \multicolumn{2}{|c|}{6} & \multicolumn{2}{|c|}{ Conservative type } & 0.52 & 1.2 \\
\hline Intention & $x_{7}$ & $x_{8}$ & $x_{9}$ & $x_{10}$ & $x_{11}$ & $x_{12}$ & $x_{13}$ & $x_{14}$ & $x_{15}$ & $x_{16}$ \\
\hline Acceleration & 34.7 & 18 & 1.55 & 5.6 & 12 & 1.1 & 116.4 & 35.4 & 5.15 & 7.11 \\
\hline Deceleration & 34.4 & 18.6 & 1.60 & 6.4 & 11 & 1 & 104.5 & 33.5 & 5.17 & 7.03 \\
\hline Constant speed & 34 & 18.8 & 1.45 & 5.3 & 11.5 & 2 & 113.4 & 35 & 4.53 & 6.73 \\
\hline Climb & 34.5 & 17.7 & 1.75 & 7.4 & 22 & 1.8 & 105.8 & 36.4 & 5.07 & 6.44 \\
\hline Descend & 33.8 & 18 & 1.65 & 7.8 & 17 & 1.1 & 112.1 & 34.3 & 4.33 & 6.75 \\
\hline Constant altitude & 33.6 & 17 & 1.80 & 3.4 & 5 & 1.2 & 108.2 & 36 & 4.74 & 7.03 \\
\hline Turn left & 35.3 & 17.6 & 1.75 & 5.7 & 7.5 & 2.1 & 110.3 & 33.8 & 3.15 & 6.54 \\
\hline Turn right & 35.5 & 16.7 & 1.70 & 5.8 & 6.5 & 2.2 & 101.2 & 34 & 3.05 & 6.72 \\
\hline Constant heading & 35.2 & 17.4 & 1.65 & 6.4 & 5 & 1 & 113.4 & 35.8 & 3.08 & 7.15 \\
\hline
\end{tabular}




\section{RESULTS}

Pilot's psychological and physiological characteristics analysis

Under the effect of various factors, the pilot has a cognitive process for the objective flight conditions. The decision-making tendency of the pilot in this cognitive process is the type of psychological characteristics. The questionnaire is applied to statically survey the pilot's psychological characteristic type in this paper. The pilot's psychological characteristic formed in the past flight experience is relatively stable. It is always under the control of brain consciousness and exists in implicit form, and is divided into the conservative, conventional, or aggressive type.

SPSS is used to statistically analyse the test results of all the subjects' psychological characteristics. The reliability and validity of the questionnaire are evaluated and the internal consistency Cronbach's Alpha is $0.879>0.8$, which shows that the questionnaire is more credible. Each question is analysed to obtain its mean and standard deviation. The correlation analysis is performed on the scores

Table 6 - The results of pilot's psychological test questionnaire of each question and the total scores, and the corresponding person correlation coefficient is obtained. The psychological test results are depicted in Table 6 .

As shown in Table 6, it can be seen that about $90 \%$ of the question scores are significantly correlated with the total scores at the 0.05 and 0.01 significance levels. This reveals that the questionnaire has higher homogeneous reliability and better validity of content and the test can be performed. The results of pilots' psychological characteristics are illustrated in Figure 8.

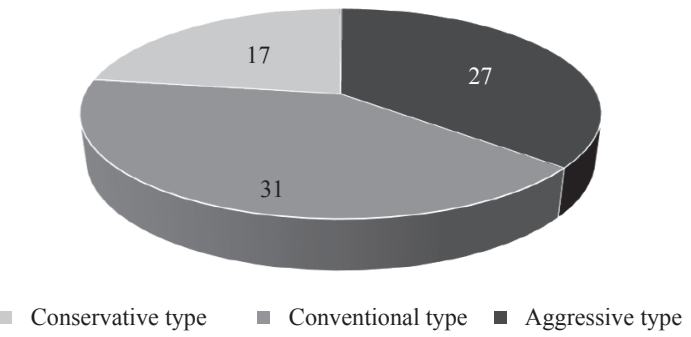

Figure 8 - The results of the pilots' psychological characteristics type test

As an organic living body, every particular gesture and behaviour of a pilot is related to the coordination and control of various systems of the body.

\begin{tabular}{||c|c|c|c|c|c|c|c||}
\hline Quest. & Mean value & $\begin{array}{c}\text { Standard } \\
\text { deviation }\end{array}$ & $\begin{array}{c}\text { Correlation } \\
\text { coefficient }\end{array}$ & Quest. & Mean value & $\begin{array}{c}\text { Standard } \\
\text { deviation }\end{array}$ & $\begin{array}{c}\text { Correlation } \\
\text { coefficient }\end{array}$ \\
\hline \hline 1 & 1.43 & 0.478 & $0.714^{* *}$ & 20 & 1.89 & 0.788 & $0.467^{* *}$ \\
\hline 2 & 2.15 & 0.813 & $0.395^{*}$ & 21 & 2.02 & 0.795 & $0.575^{* *}$ \\
\hline 3 & 3.39 & 0.956 & $0.518^{* *}$ & 22 & 1.94 & 0.562 & $0.575^{* *}$ \\
\hline 4 & 2.12 & 0.709 & $0.612^{* *}$ & 23 & 2.06 & 0.605 & $0.585^{* *}$ \\
\hline 5 & 2.03 & 0.725 & $0.543^{* *}$ & 24 & 2.15 & 0.813 & $0.387^{*}$ \\
\hline 6 & 2.01 & 0.745 & $0.414^{* *}$ & 25 & 2.03 & 0.686 & $0.669^{* *}$ \\
\hline 7 & 1.89 & 0.723 & $0.512^{* *}$ & 26 & 2.02 & 0.759 & $0.387^{*}$ \\
\hline 8 & 1.89 & 0.523 & $0.440^{* *}$ & 27 & 1.96 & 0.716 & $0.536^{* *}$ \\
\hline 9 & 1.85 & 0.768 & 0.133 & 28 & 1.95 & 0.718 & $0.648^{* *}$ \\
\hline 10 & 2.15 & 0.562 & $0.575^{* *}$ & 29 & 1.87 & 0.671 & $0.614^{* *}$ \\
\hline 11 & 2.04 & 0.686 & 0.238 & 30 & 2.00 & 0.795 & $0.594^{* *}$ \\
\hline 12 & 1.78 & 0.550 & 0.255 & 31 & 2.04 & 0.616 & $0.552^{* *}$ \\
\hline 13 & 1.82 & 0.768 & $0.412^{*}$ & 32 & 2.05 & 0.510 & $0.424^{*}$ \\
\hline 14 & 2.00 & 0.795 & $0.751^{* *}$ & 33 & 2.55 & 0.995 & $0.750^{* *}$ \\
\hline 15 & 2.04 & 0.678 & $0.548^{* *}$ & 34 & 2.05 & 0.718 & $0.640^{*}$ \\
\hline 16 & 1.98 & 0.723 & $0.714^{* *}$ & 35 & 2.08 & 0.716 & $0.451^{* *}$ \\
\hline 17 & 1.96 & 0.714 & $0.487^{*}$ & 36 & 2.01 & 0.759 & $0.649^{* *}$ \\
\hline 18 & 2.00 & 0.659 & $0.526^{*}$ & 37 & 1.96 & 0.718 & $0.580^{* *}$ \\
\hline 19 & 2.03 & 0.743 & $0.624^{* *}$ & 38 & 2.04 & 0.654 & $0.605^{* *}$ \\
\hline
\end{tabular}

* the corresponding item has a significant correlation at a level of significance of 0.05

${ }^{* *}$ the corresponding item has a significant correlation at a level of significance of 0.01 
Any kind of psychology state is accompanied by fluctuations in physiological information. Under the comprehensive effect of various factors, the visual and auditory characteristics of the pilot are compatible with the psychological characteristics. Physiological characteristics are the basic materials that constitute psychological factors, and psychological factors are ultimately reflected in the physiological characteristics of the pilots. These features are closely related to the psychological characteristics. They are physiological characteristics.

The operational response time refers to the time required to complete an operation action when the pilot is subjected to a certain stimulus [17]. In short, it is the time interval between the presentation of the stimulus and the completion of the action. The operational response time is utilized to test the subjects' agility in complex situations. In addition, it can check the ability that the pilots handle the change in continuous scenes during the flight, such as response speed and operating accuracy. It can be seen from the test results, that the overall mean value and the standard deviation of the pilot's operational response time are $0.32 \mathrm{~s}$ and $0.14 \mathrm{~s}$, respectively. The distribution of operational response time is presented in Figure 9.

The speed estimation is adopted to examine the spatial orientation and judgement ability of the subjects, and the speed estimation time is often selected as the evaluation index [16]. In the experimental sample, the data segment of speed estimation is mainly concentrated in $1.0 \sim 1.9 \mathrm{~s}$, the average value is $1.43 \mathrm{~s}$, and the standard deviation is $0.14 \mathrm{~s}$. The distribution of speed estimation time is shown in Figure 10.

\section{Analysis of pilot's movement characteristics}

The movement characteristics of pilots from one leg to the other are different in the airfield traffic pattern. Due to space limitations, the example of a flight from the crosswind leg to the downwind leg is described in detail. The randomly selected data of the pilot's movement characteristics constitutes the original data set. One-way ANOVA is used to detect whether different intentions had a significant effect on the changes in the movement parameters. If the effect is significant, a detailed analysis of the changes in movement characteristics under different intentions is performed. The results of one-way ANOVA based on Matlab are given in Table 7.

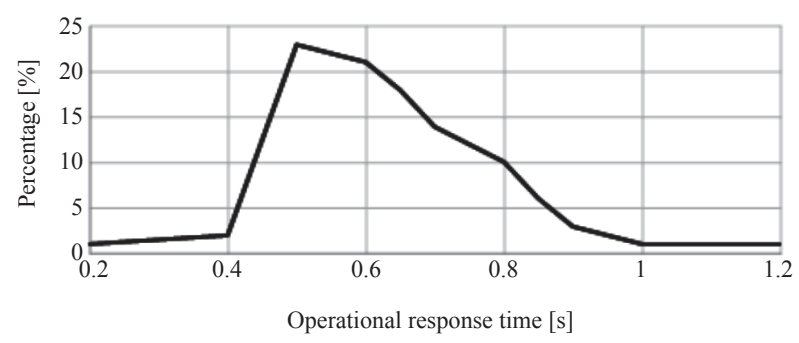

Figure 9 - The distribution of operational response time

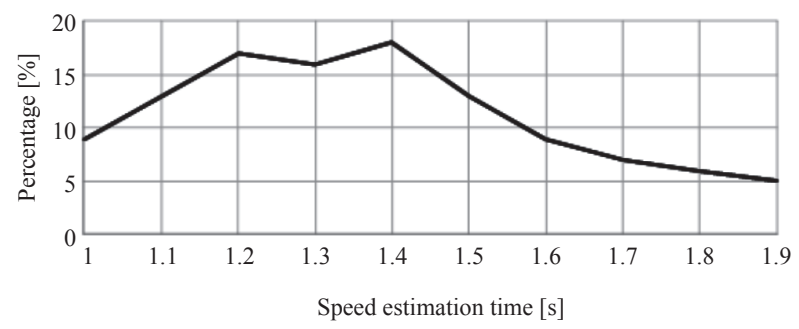

Figure 10 - The distribution of speed estimation ability

As can be seen from Table 7, the movement parameters are significantly affected by different pilot's intentions $(\mathrm{P}<0.005)$, and the statistical results are described in Figures 11-16.

From the analysis, it can be seen that the rudder pedal strength reaches the highest level under the intention of turning left, turning right and deceleration. It is weaker under the intention of acceleration, climbing and descending, and then it becomes minimum in the intention of maintaining the speed and altitude. The steering column strength is maximal while the intention of accelerating, decelerating, climbing and descending occurred, and it is smaller in the intention of turning left, turning right and maintaining speed intention. It is minimal under the intention of holding altitude and maintain heading. The climbing rate achieves the maximum under the intention of climbing and descending. It is lower under the intention of holding altitude, accelerating and decelerating, and then it reaches the minimum under the intention of maintaining speed, turning left, turning right, and maintaining heading. The acceleration frequency is the highest under the intention of accelerating, decelerating, and maintaining speed. It is lower under the intention of climbing, descending and maintaining altitude, and it is the lowest while turning left, turning right, and holding heading. The vertical speed change frequency is maximal under the intention of accelerating, decelerating and maintaining speed, and it becomes lower under the intention of climbing, descending and 
Wang H, Si H, Li Y, Pan T, Zong Y, Jiang N. Analysis of Dynamic Characteristics of Pilots Under Different Intentions...

Table 7 - Results of one-way ANOVA of pilots' movement characteristics

\begin{tabular}{|c|c|c|c|c|c|c|}
\hline & & Quadratic sum & df & Mean square & $\mathrm{F}$ & Significance \\
\hline \multirow{3}{*}{$\begin{array}{l}\text { Rudder pedal strength } \\
\qquad[\mathrm{N}]\end{array}$} & Inter-group & $9,674.400$ & 6 & 435.600 & 415.746 & 0.000 \\
\hline & Intra-group & 724.700 & 135 & 1.135 & & \\
\hline & Total & $9,348.500$ & 219 & & & \\
\hline \multirow{3}{*}{$\begin{array}{l}\text { Steering column strength } \\
\qquad[\mathrm{N}]\end{array}$} & Inter-group & $8,613.600$ & 7 & 387.700 & 356.682 & 0.000 \\
\hline & Intra-group & 575.500 & 201 & 1.156 & & \\
\hline & Total & $8,461.700$ & 236 & & & \\
\hline \multirow{3}{*}{$\begin{array}{l}\text { Climbing rate } \\
{[\mathrm{km} / \mathrm{s}]}\end{array}$} & Inter-group & $3,734.700$ & 5 & 602.500 & 375.401 & 0.000 \\
\hline & Intra-group & 219.800 & 194 & 1.201 & & \\
\hline & Total & $3,783.600$ & 203 & & & \\
\hline \multirow{3}{*}{$\begin{array}{l}\text { Accelerating frequency } \\
\text { [times/min] }\end{array}$} & Inter-group & $5,643.800$ & 7 & 798.400 & 465.324 & 0.000 \\
\hline & Intra-group & 375.68 & 234 & 1.321 & & \\
\hline & Total & $5,935.600$ & 235 & & & \\
\hline \multirow{3}{*}{ Pitch angle [deg] } & Inter-group & $8,765.500$ & 6 & 675.300 & 487.412 & 0.008 \\
\hline & Intra-group & 423.75 & 198 & 1.129 & & \\
\hline & Total & $9,658.400$ & 225 & & & \\
\hline \multirow{3}{*}{ Roll angle [deg] } & Inter-group & 23.786 & 7 & 1.234 & 170.163 & 0.007 \\
\hline & Intra-group & 1.543 & 231 & 1.008 & & \\
\hline & Total & 17.165 & 238 & & & \\
\hline \multirow{3}{*}{ Turn rate $[\mathrm{deg} / \mathrm{s}]$} & Inter-group & $23,482.500$ & 6 & 752.600 & 485.312 & 0.007 \\
\hline & Intra-group & $2,145.700$ & 186 & 1.203 & & \\
\hline & Total & $21,314.600$ & 207 & & & \\
\hline \multirow{3}{*}{$\begin{array}{l}\text { Throttle percentage } \\
{[\mathrm{deg}]}\end{array}$} & Inter-group & $9,713.512$ & 6 & 458.400 & 578.134 & 0.006 \\
\hline & Intra-group & 652.734 & 178 & 1.145 & & \\
\hline & Total & $9,675.400$ & 215 & & & \\
\hline \multirow{3}{*}{$\begin{array}{l}\text { Vertical speed change } \\
\text { frequency [times/min] }\end{array}$} & Inter-group & $26,871.531$ & 5 & 724.500 & 681.390 & 0.000 \\
\hline & Intra-group & $3,451.600$ & 257 & 1.256 & & \\
\hline & Total & $21,730.510$ & 241 & & & \\
\hline \multirow{3}{*}{$\begin{array}{l}\text { Horizontal speed change } \\
\text { frequency [times/min] }\end{array}$} & Inter-group & $28,769.500$ & 7 & 687.600 & 771.543 & 0.000 \\
\hline & Intra-group & $3,879.700$ & 274 & 1.259 & & \\
\hline & Total & $27,569.400$ & 245 & & & \\
\hline
\end{tabular}

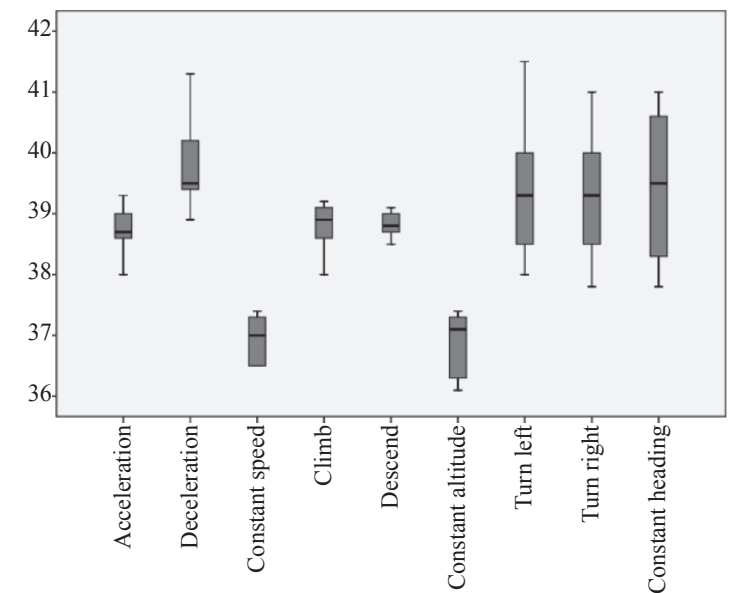

Figure 11 - Rudder pedal strength

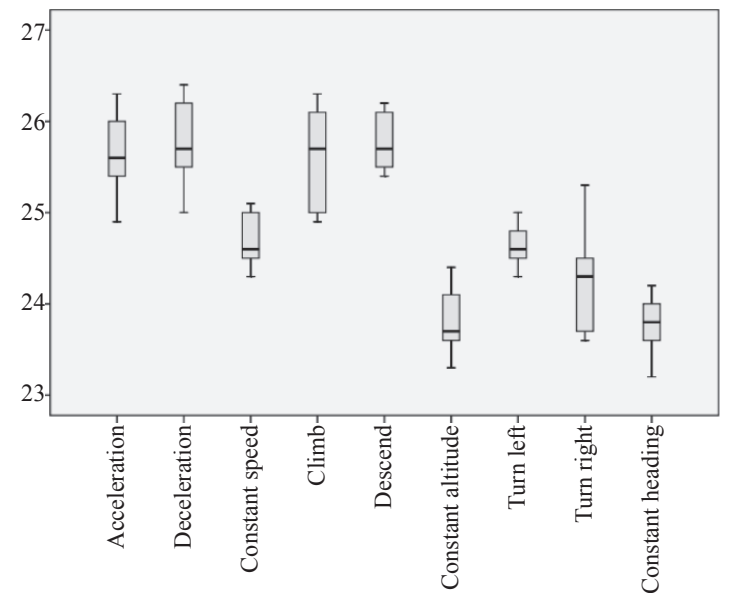

Figure 12 - Steering column strength 


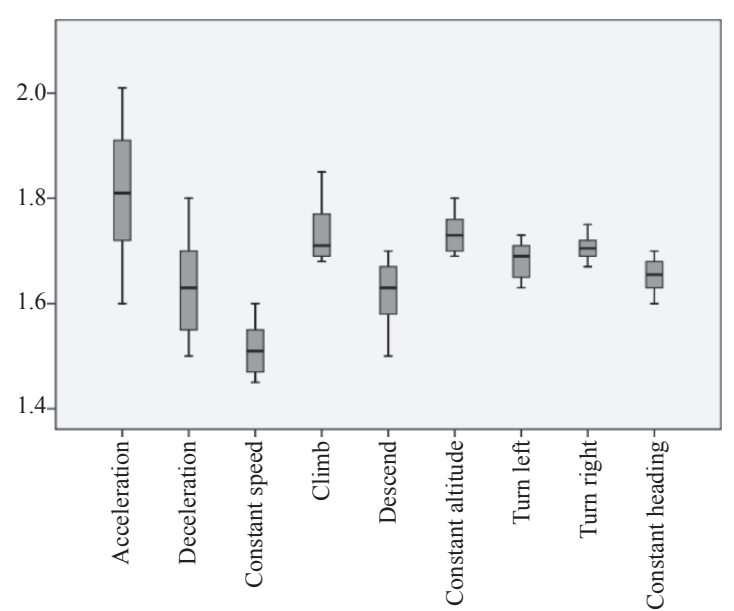

Figure 13 - Climbing rate

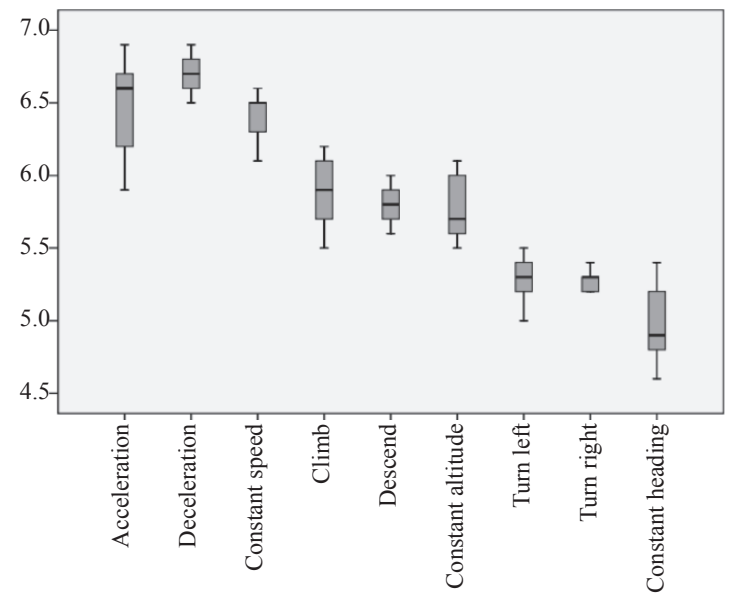

Figure 15 - Vertical speed change frequency

maintaining altitude. It turns to be the lowest while maintaining altitude and heading. The horizontal speed change frequency is the highest under the intention of accelerating, decelerating, and maintaining speed. The frequency fall appears under the intention of turning left, turning right, and maintaining heading, and reaches the minimum while under the intention of climbing, descending, and holding altitude.

\section{DISCUSSION}

The multi-source dynamic data under the effect of different intentions are obtained through the experiment in this paper. Moreover, the more representative feature parameters are selected by analysing the movement characteristics of the pilot's nine intentions in three-dimensional space. Thus, the study provides the foundation for further identification of pilot's intentions. It is understandable after the analysis that there are significant differences in rudder pedal strength, steering column strength, climbing rate, accelerating frequency, vertical speed change

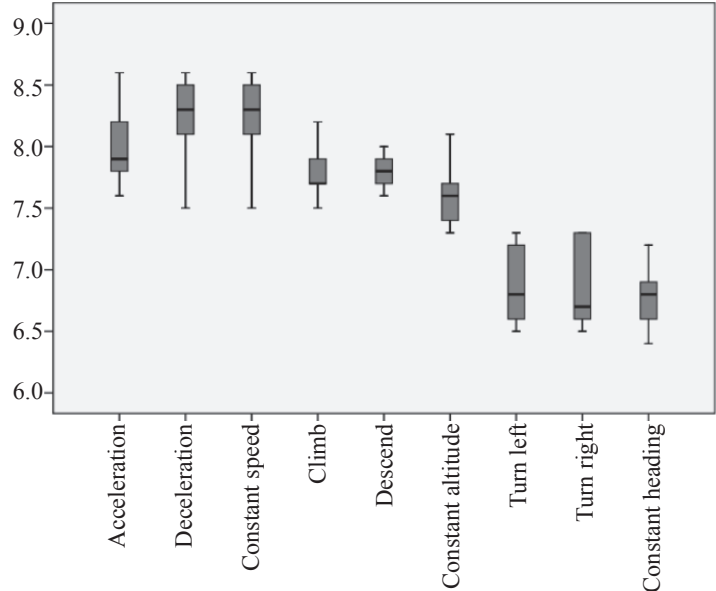

Figure 14 -Accelerating frequency

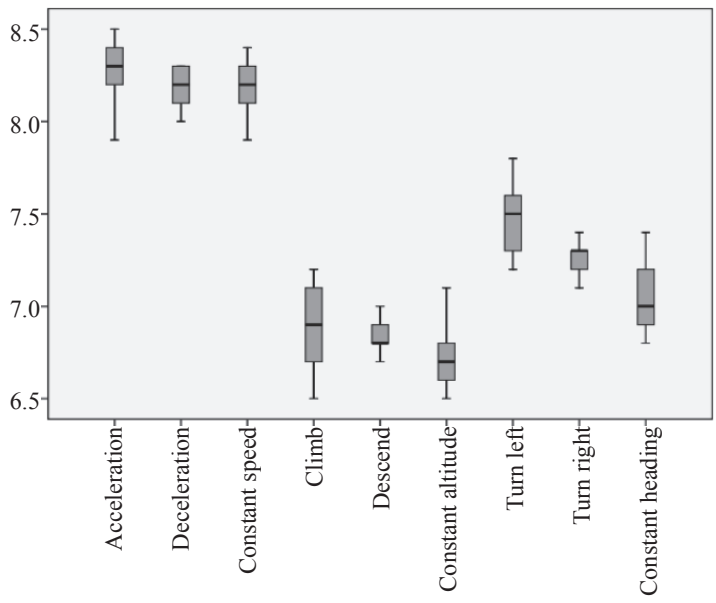

Figure 16-Horizontal speed change frequency

frequency, and horizontal speed change frequency under the pilot's different intentions during flight in airfield traffic pattern. In general, the pilot's movement characteristics change greatly under the interaction of nine intentions and then result in attitude variety of the aircraft. The pilot's radical reaction can be deduced inversely from the pilot's movement characteristics and the attitude variety of the aircraft. If the attitude of the aircraft changes slightly, the pilot is conventional. If the aircraft attitude changes slowly during the airfield traffic pattern and there is a time delay, the pilot is conservative. The conventional pilot is more conducive to control the aircraft to a stable flight attitude.

In this paper, the effect of the pilot's psychological, physiological and physical characteristics on the pilot's micro-behaviour was comprehensively considered from the change of pilot's intention. The movement characteristics of the pilot under different intentions were further analysed. The results indicated that this study can better compensate for the vacancies in the field of air traffic safety. The results 
also implied that the analysed characteristics can provide the basis for the identification of pilot's intentions. Firstly, the movement characteristics of pilots during the airfield traffic pattern were explored in this paper. Secondly, the complex conditions such as wind shear and thunderstorm often faced in the process of taking off, cruising, and landing of the aircraft need to be further discussed in future studies. Finally, it only defines and studies the generation, transfer and reduction of intentions statically, and does not study their dynamic changes during a complex flight.

\section{CONCLUSION}

The pilot's intention is an important factor that affects the aircraft operation. There are obvious differences in the movement characteristics of the pilot under different intentions. This paper studies the pilot's movement characteristics under the effect of nine intentions. The multi-source dynamic data of human - aircraft - environment was obtained through the experiment. Afterwards, the psychological, physiological and physical characteristics of the pilots were gathered statistically, and one-way analysis of variance was applied to screen aircraft operating variables that varied significantly due to differences in intention. There is a comparative analysis of the pilot's movement characteristics under different intentions. This study lays the theoretical foundation for further study of pilot's intention identification. With the upgrade and development of the aircraft cockpit, the active safety warning system is becoming increasingly intelligent. Emerging multichannel interactive technologies such as somatosensory interaction, eye tracking, voice interaction and biometric recognition will be widely used in the upgrade and development of aircraft cockpits to enhance further the active safety warning system. The active safety warning system will obtain and analyse the multi-source dynamic information of different pilots in the human - machine - environment interaction process. In this way, targeted early warnings for different pilots can be achieved according to different flight environments, so as to avoid various pilots being overwhelmed when facing dangerous situations. What is more, the analysis of the dynamic characteristics of pilots under different intentions in the complex flight environment will improve the comprehensive understanding of the psychological, physiological, and physical characteristics of the flying cadet, and the pilot's micro-behaviour assessment system. Therefore, this study is of great practical significance to research the future active safety warnings for flight and the pilot's micro-behaviour assessment.

\section{ACKNOWLEDGEMENTS}

This study has been supported by the Funding for Outstanding Doctoral Dissertation in NUAA (Grant NO. BCXJ19-10) and Postgraduate Research \& Practice Innovation Program of Jiangsu Province (Grant NO. KYCX19_0196).

汪海波 ${ }^{1}$, 博士

电子邮箱: sdlgwanghaibo@sohu.com

司海青 ${ }^{1}$ (通讯作者), 教授, 博士

电子邮箱: sihaiqing@126.com

李耀 1 , 博士

电子邮箱: liyao33355555@163.com

潘亭 ${ }^{1}$, 博士

电子邮箱: panting3721@163.com

宗奕粀 1

电子邮箱: yitongzyt @163.com

姜乃琪 ${ }^{1}$

电子邮箱: woshitiancai0816@163.com

1 南京航空航天大学 民航学院/飞行学院, 南京市, 江苏省, 中国

\section{复杂飞行环境中不同意图作用下飞行员动态特 征分析}

摘要

意图是人脑意识活动的主要体现形式, 对指导 人类行为的实现具有重要影响。分析不同飞行意图 下飞行员的动态特征是进一步研究飞行员意图的重 要前提。基于此, 本文从飞行员意图的影响因素入 手, 综合考虑意图的产生、转移、消退等规律, 对 不同意图下的飞行员动态特征进行了分析, 以飞行 员本场五边飞行为例进行实机与模拟飞行实验, 采 集飞行员在不同意图作用下的人-机-环境系统多源动 态数据, 对飞行员心理-生理-物理特征进行统计, 并 基于Matlab运用单因素方差分析法提取出因意图差 异而显著变化的变量, 并对不同意图下的各变量进 行对比分析。该研究为完善飞行安全预警系统、健 全飞行员微观行为考核与评价系统具有重要意义。

\section{关键词}

飞行安全; 飞行员意图; 动 特征; 单因素方差分析

\section{REFERENCES}

[1] Degani A, Heymann M, Meyer G, Shafto M. Some Formal Aspects of Human-Automation Interaction. Moffett Field, CA: NASA Ames Research Center TM 2000209600; 2000.

[2] Crow J, Javaux D, Rushby J. Models and Mechanized Methods that Integrate Human Factors into Automation Design. Proceedings of the International Conference on Human-Computer Interaction in Aeronautics: HCI-Aero, 
27-29 Sep 2000, Toulouse, France. Tolosa Press; 2000. p. $163-168$.

[3] Final Report of the Accident Investigation Flash Airlines Flight 604, Boeing 737-300, SU-ZCF, January 3, 2004, Red Sea near Sharm El-Sheikh, Egypt. Egyptian Ministry of Civil Aviation, Final Investigation Report, Cairo, Egypt, 2004.

[4] Report on Accident to Indian Airlines Airbus A-320 Aircraft VT-EPN at Bangalore on 14th February 1990. Indian Court of Inquiry, Indian Government, Final Investigation Report, New Delhi, India, 1992.

[5] Wilson GF. An Analysis of Mental Workload in Pilots during Flight Using Multiple Psychophysiological Measures. International Journal of Aviation Psychology. 2002;12(1): 3-18.

[6] Schlimm KA. A Model for Situational Awareness in Aircraft Upset Prevention and Recovery. $15^{\text {th }}$ AIAA Aviation Technology, Integration, and Operations Conference, 2226 June 2015, Dallas, TX; 2015.

[7] Zhang L, Zhang W, Zhu Z, Ding L. Probing into the evaluation of flight training in special environment based on EMGs. Procedia Manufacturing. 2015;3(18): 4493-4500.

[8] Jia B, Wei CF, Mao JF, Law R, Fu S, Wu Q. Identification of flight state under different simulator modes using improved diffusion maps. Optik. 2016;127(9): 3905-3911.

[9] Marinescu A, Sharples S, Rithie C, Sanchez LS, McDowell M, Morvan H. Exploring the Relationship between Mental Workload, Variation in Performance and Physiological Parameters. $3^{\text {th }}$ IFAC Symposium on Analysis, Design, and Evaluation of Human-Machine Systems HMS. 2016;49(19): 591-596.
[10] Olivari M, Venrooij J, Nieuwenhuizen FM, Pollini L, Heinrich H. Identifying Time-Varying Pilot Responses: a Regularized Recursive Least-Squares Algorithm. 2016 AIAA Modeling and Simulation Technologies Conference, 13-17 June 2016. Washington, D.C; 2016.

[11] Tavcar A, Kuznar D, Gams M. Hybrid Multi-Agent Strategy Discovering Algorithm for human behaviour. Expert Systems with Applications. 2017;71: 370-382.

[12] Jaquess KJ, Gentili RJ, Lo LC, Hatfield B. Empirical evidence for the relationship between cognitive workload and attentional reserve. International Journal of Psychophysiology. 2017;121: 46-55.

[13] Lampton AK, Klyde DH, Schulze PC. Evaluation of a Missed Approach/Go-Around Spatial Disorientation Demonstration Scenario for Commercial Pilot Training. 2017 AIAA Modeling and Simulation Technologies Conference, 9-13 January 2017, Grapevine, Texas; 2017.

[14] Russi-Vigoya MN, Patterson P. Analysis of pilot eye behaviour during glass cockpit simulations. Procedia Manufacturing. 2015;3: 5028-5035.

[15] Wang XY, Liu YQ, Wang JQ, Zhang JL. Study on Influencing Factors Selection of Driver's Propensity. Transportation Research Part D. 2019;66(1): 35-48.

[16] Sun R, Peng T. Design of Flight Cognitive Ability Measurement Scheme and Its Model. China Safety Science Journal. 2010;20(11): 47-51.

[17] Hadder EM, Takahashi TT. Minimum Control Speed Estimation for Conceptual Design. 17th AIAA Aviation Technology, Integration, and Operations Conference, 5-9 June 2017, Denver, Colorado; 2017. 